\title{
DISCURSO DA LUTA CONTRA A VIOLÊNCIA: O PORTE DE ARMAS E OS SEUS EFEITOS DE SENTIDO
}

\section{ELIZANGELA ARAÚJO DOS SANTOS FERNANDES ${ }^{1}$, THIAGO BARBOSA SOARES ${ }^{2}$}

Programa de Pós-Graduação em Letras (PPGLetras)

Universidade Federal do Tocantins

Jardim dos Ipês, Rua 03, Q. 17, s/nº 77500 - 000 | Porto Nacional/TO, Brasil

\author{
elizangelabibi2@yahoo.com.br, thiago.soares@mail.uft.edu.br
}

\begin{abstract}
Resumo: Este artigo tem por objetivo empreender uma análise a respeito dos dizeres do presidente Jair Bolsonaro sobre o porte e a posse de armas no Brasil e os seus posicionamentos acerca da violência no país. Desse modo, tomaremos como base o aparato teórico-metodológico da Análise do Discurso francesa, especificamente as noções de formações discursivas, ideológicas, as memórias discursivas, as fronteiras da linguagem tratadas como silêncio, bem como as posições-sujeito que o chefe de governo assume ao proferir dizeres sobre o decreto 9785/2019. Nesse sentido, faremos uma investigação em diferentes veículos midiáticos brasileiros, tais como o site Agência Brasil (2019), Portal de Notícias G1(2019), e o Estadão (2019).
\end{abstract}

Palavras-chave: Análise do discurso; Política; Discurso de violência.

\begin{abstract}
This article aims to undertake an analysis about Jair Bolsonaro's sayings regarding gun license and possession of firearms in Brazil also his discursive position on violence in general in the country. Therefore, we'll use as foundation the theoretical and methodological apparatus of French discourse analysis, specially the concept of discursive formations, ideological formations, discursive memories, language limits treated as silence, as well as the subject-position that the president of Brazilian government adopts by positioning discursively about the decree $n^{o}$ 9785/2019. For that matter, an investigation have been done in different Brazilian media sources, such as Agência Brasil (2019), Portal de Notícias G1 (2019) and Estadão (2019).
\end{abstract}

Keywords: Discourse analysis; Politics; Violence discourse.

\section{INTRODUÇÃO}

A problemática sobre o porte e a posse de armas é discutida no país por conta das mudanças na legislação feitas pelo atual presidente Jair Bolsonaro, atendendo às

\footnotetext{
${ }^{1}$ Mestranda em Letras (PPGLetras) pela Universidade Federal do Tocantins (UFT), campus de Porto Nacional - TO.

2 Doutor em Linguística pela Universidade Federal de São Carlos (UFSCar) e professor nos cursos de graduação em Letras e de pós-graduação stricto sensu em Letras da Universidade Federal do Tocantins (UFT) no campus de Porto Nacional.
} 
promessas de campanha, por meio de decretos presidenciais. Ele flexibilizou a posse de armas no Brasil e o principal ponto alterado por Bolsonaro, considerando o seu compromisso com o povo, é em relação à efetiva necessidade, entendida por ele como um requisito subjetivo. As alterações promovidas na posse de arma pelo decreto têm gerado debate e produzido dizeres por parte do referido presidente e serão alvo de nossa investigação.

Nesse sentido, cabe ressaltar que a discussão sobre o direito de possuir armas é antiga no Brasil e há quem o defenda e o repudie. Segundo uma pesquisa do Instituto Datafolha realizada em dezembro de 2018, com 2.077 pessoas, em 130 municípios, $61 \%$ dos brasileiros são contrários à posse de armas. Esta parcela da população alega que é função do Estado e suas forças policiais, e não do cidadão comum, lidar com a segurança e a criminalidade, bem como argumentam que O Referendo de 2005 (ao qual a maior parte da população foi favorável) diz respeito ao comércio e não à posse de armas.

Quanto aos argumentos dos defensores dessa prática, observa-se como justificativa ser uma proposta que foi legitimada via eleição democrática, já que a medida vai ao encontro do Referendo realizado em 2005, no qual mais da metade da população votou pelo comércio de armas. Os apoiadores ainda afirmam que o Estatuto do Desarmamento não cumpriu sua função, pois não reduziu significativamente os índices de homicídio.

Diante das alegações acima, temos o discurso político sobre a violência que possui como característica uma significativa, senão absoluta, mudança na organização da sociedade e de seu funcionamento. Esse tipo de discurso é, por excelência, dotado de persuasão. Na utilização de procedimentos retóricos e linguísticos, o enunciador cria nos seus interlocutores uma confiança através da interação comunicativa. Sendo assim, entre a verdade do dizer e uma verdade do fazer, o discurso político constitui-se do logos (argumento) sendo o próprio discurso, as propostas e os argumentos apresentados pelo ator político nos assuntos discutidos (CHARAUDEAU, 2008a); o ethos (imagem), corresponde à autoimagem que se institui perante seus interlocutores; e o pathos (paixão) volta-se para o sentimento que o agente político busca conquistar o povo pela demonstração de proximidade e preocupação com o problema social em questão (ARISTÓTELES, 1998).

Seguindo essa associação do logos, ethos e pathos, nosso principal objetivo é descrever e interpretar à luz da análise do discurso francesa os mecanismos constituintes do processo enunciativo-discursivo nos pronunciamentos de Bolsonaro na mídia brasileira acerca do armamento civil, já que "entre as formas de criar a imagem de si no discurso encontra-se o dizer e, sobretudo, como esse é feito e quais os mecanismos de produção estão presentes em sua enunciação" (SOARES; SANTOS, 2021, p.2). Neste estudo analisaremos o posicionamento do atual presidente e as discursividades que carrega ao referir-se ao combate à violência, de modo a mostrar os dizeres do chefe do executivo pautados em formações discursivas a serem investigadas. A partir dessa perspectiva, o corpus será formado por enunciados de textos midiáticos recortados da mídia jornalística veiculados entre janeiro de 2018 a junho de 2019 que evidenciam a reverberação com que tais discursos são proferidos. 
Para que se possa alcançar tal objetivo, nossa escolha é motivada pelo elevado número de produções discursivas polêmicas enunciadas pelo Presidente na mídia brasileira, tornando-as objeto de interesse na busca pelo conhecimento das características do uso das estratégias discursivas do discurso político. A estratégia mais expressiva neste trabalho é a justificativa das práticas do presidente em nome do "povo" e do "cidadão de bem" por meio de diferentes funcionamentos linguísticos e discursivos, visando o mesmo objetivo: uma imagem altruísta. Para interpretarmos os efeitos de sentidos e como esses são fabricados nessas produções textuais-discursivas, neste estudo, portanto, observaremos a intersecção dos conceitos de Pêcheux (2010, 2011) e Orlandi (2015) no sentido de apresentar que o discurso não é gestado no vazio, como também não existe ingenuidade no dizer. Ancoramo-nos, ainda, no arcabouço teórico cunhado por Patrick Charaudeau (2005, 2008, 2016), de modo que possa contribuir para a compreensão do ethos, logos e pathos no discurso político, além de possíveis contribuições teórico metodológicas de outros analistas de Discurso.

\section{A ANÁLISE DO DISCURSO FRANCESA}

A análise do discurso francesa surgiu nos anos 60 e tem como principal teórico e entusiasta o filósofo Michel Pêcheux. Nessa época, que coincide com o auge do estruturalismo como paradigma de formatação do mundo, das ideias e das coisas para toda uma geração da intelectualidade, no caso francesa, Pêcheux projetou suas pesquisas articuladas entre a linguística, o materialismo histórico e a psicanálise. Podemos então afirmar que o filósofo francês intentava, de acordo com Paul Henry "abrir uma fissura teórica e científica no campo das ciências sociais, e, em particular, da psicologia social" (HENRY, 2010, p. 12). A partir desse viés, a AD traz "um dispositivo teórico e de análise que permitirá tornar visíveis as afinidades e/ou diferenças na interlocução com outros saberes" (FERREIRA, 2010, p. 20). Nesse interim, Pêcheux dedica-se ao conceito de discurso e foi ao extremo no sentido de debater o discurso enquanto objeto de um dispositivo de análise e interpretações. Desse modo, seu objetivo era sistematizar o conhecimento no desenvolvimento de um novo instrumento capaz de estudar as ciências humanas com método, rigor e objeto estabelecidos. Essa estrutura teórica e de reflexão possibilitou o início de uma nova teoria, Teoria do Discurso, enquanto propulsora da produção dos efeitos de sentido.

A análise do discurso não é uma disciplina autônoma, nem auxiliar (ROBIN, 1986), sendo, pois, uma disciplina de entremeio. Sua finalidade é tematizar o objeto discursivo como um objeto que se encontra nos limites das grandes divisões disciplinares, constituindo-se de uma materialidade linguística e de uma materialidade histórica, simultaneamente. Nesse sentido, os estudos de Pêcheux voltam-se para o ponto de entrelaçamento entre a linguagem e a ideologia que chega pelo viés do materialismo histórico e recebe um lugar de destaque na área do discurso, sendo considerado indissociável do sujeito em um processo de constituição mútua, tal como afirmam Pêcheux e Fuchs (1997, p. 167), pois, segundo eles “[...]'a ideologia interpela os indivíduos em sujeito': esta lei constitutiva da Ideologia nunca se realiza 'em geral', mas sempre através de um conjunto complexo determinado de formações ideológicas". O sujeito não é o centro do discurso, nem tampouco produtor de sentidos. Mas, a posição que o sujeito assume é determinada pela sua inscrição ideológica, ou seja, o sujeito é assujeitado e, ao ser posicionado dentro de formações ideológicas, não tem controle dos efeitos de sentido do que diz, contudo, ele é responsável por direcionar os 
sentidos no interior de uma formação discursiva dada, na qual se inscreve (ORLANDI, 2015).

Frente a esse entendimento, as formações discursivas são conceituadas como "um conjunto complexo de atitudes e representações que não são individuais nem universais, mas se relacionam mais ou menos diretamente a posições de classes em conflito umas com as outras" (HAROCHE; HENRY \& PECCHEUX, 2007, p. 26). Por esse ângulo, pode-se verificar que as formações ideológicas mantêm uma relação inerente às formações discursivas. É através das formações ideológicas que os sujeitos se inscrevem dentro das formações discursivas a partir de uma posição dada que determina o que pode e deve ser dito (PÊCHEUX, 2011).

Para a análise do discurso pecheutiana, o sujeito inscreve-se em uma formação discursiva e passa a ocupar, não mais o lugar de sujeito empírico, mas sim o de sujeito do discurso que carrega consigo marcas do social, do ideológico, do histórico e tem a ilusão de ser a fonte do sentido, Pêcheux e Fuchs ([1975] 1997). E, é nesse processo discursivo que os sujeitos e os sentidos se constituem por meio de transferências e jogos simbólicos. Nesse entrelaçamento não existe um controle e vê-se logo o papel da ideologia e do inconsciente marcados pelo equívoco (ORLANDI, 2015).

É importante destacar ainda, neste trabalho, o papel da memória discursiva defendida por Pêcheux ao apontar que

a memória como estruturação de materialidade discursiva complexa, estendida em uma dialética de repetição e regularização: a memória discursiva seria aquilo que, face, a um texto surge como acontecimento a ler, vem a restabelecer os 'implícitos' de que sua leitura necessita: a condição do legível em relação do legível (PÊCHEUX, 1999, p. 52)

Como se abstrai da afirmativa mencionada vê-se que é na memória discursiva que toda formação discursiva passa a produzir e operar formulações feitas anteriormente. Dito de outro modo, a memória discursiva possibilitará uma infinita rede de formulações presentes no intradiscurso de uma formação discursiva, tais como o aparecimento, a rejeição ou a transformação de enunciados que pertencem a formações discursivas historicamente posicionadas. Diante do exposto, Pêcheux (1999, 1975) reitera que todo discurso se constitui a partir de uma memória e do esquecimento. Assim, a memória é considerada o saber discursivo, o já-dito, os sentidos que não se tem mais acesso, no entanto, sem pedir licença, estão nos sujeitos.

Nessa conjuntura, a memória discursiva autoriza a repetição ao possibilitar que toda formação discursiva produza e opere formulações anteriores, já enunciadas, repetindo os pré-constituídos, ou seja, "o efeito subjetivo de anterioridade" (HENRY, 1990, p. 61). Em outras palavras, "o que remete a uma construção anterior, exterior, mas sempre independente, em oposição ao que é construído pelo enunciado" (PÊCHEUX, 1988, p. 99), deslocando-se, reinventando-se, reconstruindo-se e desdobrando-se em face de um acontecimento que a impele a isso. Para Pêcheux (1999), a memória é móvel ao assumir duas funções que operam de formas contrárias entre si, pois, se, por um lado, retoma o passado; por outro, elimina-o. 
Com efeito, a linguagem é marcada pela incompletude (CARNEVALE, 2015). Para se promover a compreensão de um texto, é necessário saber que todas as informações não são fornecidas pois, ao falar, o sujeito realiza escolhas reguladas por determinada formação ideológica. Nesse prisma, o funcionamento do discurso acontece pelos processos de repetição que mantêm entre si relações de sentido (ORLANDI, 2001). "A noção de memória discursiva diz respeito à existência histórica do enunciado no seio de práticas discursivas, reguladas pelos aparelhos ideológicos" (COURTINE, 1981, p. 53). Em uma formação discursiva, a memória permite a lembrança, a repetição, pois está na base da produção discursiva. Nessa toada, as noções de memória e interdiscurso recobrem-se, se concebermos esta última como "todos os dizeres já ditos e esquecidos - em uma estratificação de enunciados que, em seu conjunto, representa o dizível" (ORLANDI, 2015, p. 30 e 31).

É fundamental compreendermos que o interdiscurso fornece, segundo Courtine (1999, p. 20), "formulações constitutivas de uma relação imaginária no momento da enunciação com o domínio da memória". A partir dessa perspectiva, como se verifica, não existe sujeito no interdiscurso, mas posições de sujeito que regulam o ato de enunciação conforme a posição ideológica assumida pelo enunciador. Enquanto o intradiscurso, esse funciona como a memória do dizer e materializa-se na fala, ou seja, é a formulação do texto que se encontra no fio do discurso e sua linearização. Podemos considerar, então, os apontamentos que Orlandi (2015) traz ao afirmar que o intradiscurso é o eixo da formulação, isto é, aquilo que estamos dizendo naquele momento dado, em condições dadas.

Outro importante intelectual que muito contribuiu para formulação de uma teoria do discurso foi Patrick Charaudeau. Distanciando-se do Materialismo Histórico que tanto embalsamou os conceitos de Pêcheux, Charaudeau propôs-se a pensar o discurso a partir de estratégias discursivas de persuasão e convencimento. Portanto, para que o enunciador consiga persuadir seu auditório, ele deve apropriar-se das três características produzidas através do discurso como meios persuasivos: logos, etos e pathos. Estas características são utilizadas no discurso político, pois "Vê-se que a persuasão usada pelo discurso político relaciona-se com a paixão, com a razão e com a imagem" (CHARAUDEAU, 2008a, p.93), constituindo, assim, o triângulo da dramaturgia política.

Podemos asseverar que a argumentação e a sua funcionalidade, os mecanismos da comunicação e as estratégias persuasivas como importantes traços da teoria de Charaudeau, nos auxiliam no sentido de amparo ao que se pretende realizar na presente análise. Na próxima seção, observaremos os pronunciamentos do presidente Jair Bolsonaro e a utilização de recursos retóricos e procedimentos linguísticos como meios de persuasão, na tentativa de obter apoio daqueles que o representa.

\section{O TRABALHO DISCURSIVO DE BOLSONARO: ARMAMENTO INDIVIDUAL PARA O POVO}

Uma das principais bandeiras de campanha do presidente Jair Bolsonaro referiase à flexibilização do porte de armas (direito de carregar arma) e a posse (poder ter uma arma em casa) para a população, incluindo, ainda, a ampliação do conceito de excludente de licitude. Em seu plano de governo, ele pretendia reformular o Estatuto do 
Desarmamento. Para o atual presidente, essas medidas justificam-se pela situação de violência que o Brasil atravessa, sendo sua postura em favor de medidas repressivas no combate à criminalidade.

No dia 29 de dezembro de 2018, em sua conta no Twitter, Bolsonaro afirmou por decreto: "pretendemos garantir a posse de arma de fogo para o cidadão sem antecedentes criminais, bem como tornar seu registro definitivo". Já em 7 de maio de 2019, é assinado pelo presidente o primeiro documento chamado de Decreto da Nova Regulamentação do Uso de Armas e Munições de número 9785, de 2019. A partir desse primeiro decreto próarmamento, seguiram-se uma série de mudanças que culminaram em outras propostas armamentistas, dentre elas o Projeto de Lei 3723/19 que permite a concessão de porte de arma de fogo por meio de decreto presidencial.

Tecido esse esclarecimento, o texto que ora se inicia está situado nos argumentos do presidente Jair Bolsonaro sobre a posse e o porte de arma e suas atitudes como representante do povo brasileiro. Assim, este trabalho busca também problematizar as decisões do Chefe do Executivo Nacional em nome dos cidadãos de bem e o efeito homogeneizante entre a produção enunciativa dele e uma parcela da população brasileira.

Levando em conta essas considerações introdutórias, passemos, então, à primeira análise da materialidade que consiste na notícia veiculada no Site Agência Brasil, em 14/6/2019:

Quem está perdendo não sou eu não. Eu tenho porte de arma porque eu sou capitão do Exército. Quem está perdendo é o povo que quer arma, esse povo que, em 2005, foi lá no referendo e votou pelo direito de comprar armas e munições e o governo do PT simplesmente ignorou, passou por cima disso ${ }^{3}$.

Na sequência discursiva "Quem está perdendo não sou eu não", o enunciador se vale do advérbio de negação "não" para mostrar um privilégio, a posse e o porte de armas, que parece ser só dele, naquela condição discursiva, na posição de capitão do exército, produzindo um ethos de superioridade, ao mesmo tempo que constrói para si uma imagem altruísta. As formas linguísticas estão imbricadas a um funcionamento em que o sujeito se coloca como agente exclusivo, isso é o que se define como relações de força. Dito de outro modo, o sujeito discursivo fala a partir do lugar de militar e assim as suas palavras significam de modo diferente (ORLANDI, 2015), ou deveria ser, na posição de líder de um país, posição esta que não lhe confere a posse e o porte de armas.

No funcionamento discursivo "Eu tenho porte de arma porque eu sou capitão do Exército" é preciso jogar com aquilo que não se inscreve linguisticamente no fio deste dito (DUCROT, 1987). Este "eu sou capitão do exército" ecoa uma apropriação hierarquizada, de um modus operandi de transmissão de seu domínio, elegendo uma forma de prestígio frente aos demais sujeitos. Esta formulação corrobora $o$ entendimento do politicamente correto. $\mathrm{O}$ enunciador, ora posiciona-se como

\footnotetext{
${ }^{3}$ AgênciaBrasil, Brasília, 14 de jun. de 2019: Disponível em: http://agenciabrasil.ebc.com.br/politica/noticia/2019-06/bolsonaro-critica-decisao-do-senado-de-sustardecreto-de-armas. Acesso em: 12 de jan. de 2020.
} 
presidente, líder de uma nação, ora como capitão líder de um exército, isto é, as duas posições assumidas apontam a legitimação na manutenção do poder e o modo como ele se organiza, distribuindo posições de ordem e soberania (ORLANDI, 2015).

Chama maior atenção, contudo, a seguinte asserção do presidente: "Quem está perdendo é o povo que quer arma, esse povo que, em 2005, foi lá no referendo e votou pelo direito de comprar armas e munições e o governo do PT simplesmente ignorou, passou por cima disso". Nos argumentos "esse povo que", o pronome relativo "que" detém uma autonomia relativa ao retomar "esse povo", carregando um imaginário de unidade mobilizado por sentidos em relação àqueles que votaram no SIM a favor do armamento. Dito em outras palavras, o decreto 9875/2019 apenas se destina aos que em 2005 concordaram com a posse e o porte de armas? Se assim for, o efeito totalizador de povo, marcado por um imaginário de unidade, é quebrado. O singular de povo em "Quem está perdendo é o povo que quer arma" dissimula a heterogeneidade, mobilizando uma homogeneização que supõe estancar a contradição. Ao significar "povo que quer arma", o dizer de Bolsonaro produz sentidos que projetam àqueles que comungam com o discurso do ódio, da guerra, da morte e, desse modo, o funcionamento de "povo" apaga outros setores da população que contestam o porte e a posse de armas como forma de combate à violência.

A produção enunciativa no interdiscurso "passou por cima disso" ancora-se no pré-construído: Governo Lula que defende uma ideologia antidemocrática, a favor dos criminosos, da violência, pois defende bandido. Tais dizeres pressupõe uma postura discursiva ofensiva à esquerda que é contra a ordem e sempre desrespeita a Lei Maior de seu país, mobilizando os sentidos do não cumprimento à legalidade do Referendo em 2005. Dito em outros termos, o governo do PT não cumpriu o que preceitua o artigo 14 da Constituição Federal de 1988, regulamentado pela lei 9.709/98 que sujeitou o artigo 35 do Estatuto do Desarmamento à aprovação da população. Somada a essa ocorrência, é possível visualizarmos a estrutura interdiscursiva mobilizada nos dizeres do sujeito enunciador "passou por cima disso" com um efeito deletério do governo do PT, ao mostrar desvio de conduta deste ao violar a Carta Magna de modo a provocar uma reação emocional que amplia o sentimento de repulsa - indignação da população em relação, não apenas ao agente político Lula, mas a todos os representantes do partido.

Atentemo-nos, ainda, ao procedimento retórico e estratégias argumentativas utilizadas por Bolsonaro ao afirmar que "o governo do PT simplesmente ignorou". Nestes vocábulos é perceptível uma situação que afere rivalidade ao embate no interior de um discurso reacionário ao Estatuto do Desarmamento sancionado pelo ex-presidente Luís Inácio Lula da Silva, em 2003, como também a posição de Lula sobre o Referendo em 2005 ao declarar "Eu acho que uma pessoa comum ter arma não vai dar segurança, por isso eu votei no sim”. Os itens lexicais "o governo do PT simplesmente ignorou” provocam a percepção disfórica do absurdo, de uma tópica fora do lugar, inconcebível que leva o povo a interrogar: Como um representante da nação brasileira e seu partido negaram um direito adquirido no referendo em 2005? Apensa a fala do presidente Bolsonaro gera-se um efeito de ausência de neutralidade como princípio ético de um governante.

É interessante percebermos que a formulação "Eu acho que uma pessoa comum ter arma não vai dar segurança, por isso eu votei no sim”, dita pelo ex-presidente Lula, 
anui através da dialética da negação, um fio do discurso de segregação que não converge para uma igualdade jurídica, posto que no enunciado "Eu acho que uma pessoa comum ter arma não vai dar segurança", os sintagmas "pessoas comuns" atribui um efeito de desfavorecimento a algumas pessoas e favorecimento a outras ao direito de possuir armas. Ou seja, as práticas que mascaram os conflitos entre as classes sociais permanecem, só mudam as táticas de dominação. Percebemos, dessas considerações, as relações de força que derivam desse imaginário (ORLANDI, 2015). Logo, o atravessamento de sentidos presente na figura das pessoas comuns é que elas estão associadas à submissão dos órgãos de segurança pública - polícia para se protegerem, fazendo parte desse imaginário social (ORLANDI, 2015).

Nesse cenário de condições desiguais, no que se refere à igualdade jurídica, um desequilíbrio social é fortalecido, como se a segurança só fosse alcançada com as armas nas mãos de alguns. $\mathrm{O}$ enunciador Lula reproduz, conquanto, que para haver segurança no país basta que as armas estejam sob o comando de uma parcela da população que não são pessoas comuns. Neste contexto enunciativo, flagra-se o funcionamento da máxima pêuchetiana de que as palavras mudam de sentido conforme as posições sustentadas por aqueles que as empregam (PÊUCHEUX, 2011). Depreende-se dos dizeres de Lula "pessoas comuns portarem armas não vai dar segurança", ao que parece essas pessoas comuns passam por um tratamento de desconfiança, de quem vai causar problemas ao portar uma arma que - consequentemente - geraria insegurança, caracterizando mais violência, mais vítimas, mais mortes. Nota-se dessa maneira a força das posições discursivas deslocando esses sentidos e ajustando o imaginário social (ORLANDI, 2015). Ora, então, nesse viés enunciativo tem-se que as pessoas consideradas incomuns podem possuir armas porque não contribuem para aumentar a insegurança? Em vista disso, não haveria a necessidade de modificar a lei de segurança no país, pois o direito já se encontra positivado nas mãos de quem realmente tem a capacidade de garantir a segurança nacional e isso só é possível enxergar através da verificação dessas relações de forças, de sentido e, sobretudo da importância que tem as posições discursivas nas ressiginificações dos sujeitos e dos sentidos (PÊCHEUX, 1998).

Através de gestos analíticos, é possível entender como os enunciados se entrecruzam, de modo a identificar suas condições de possibilidade e de produção, seus princípios de regularidade e suas apropriações. No encandeamento sintático "por isso eu votei no sim", o sujeito Lula acaba por trazer uma parte de visibilidade para si, em um movimento de dupla significação: o SIM afirma uma política pública de segurança contra a violência como também há uma influência do "eu" aí muito forte, pois se expande além da pessoa estrita e amplia-se na interpelação ideológica para uma parcela significativa da população que se posicionou deste lado. Ao fazer uma leitura da fala do sujeito, observa-se que há fatos silenciados no processo discursivo pela ordem do não dito (ORLANDI, 2007). Atenta-se que o enunciador, no intuito de fortalecer seu ponto de vista, fundamenta e legitima a manutenção das armas nas mãos dos órgãos de segurança pública, sempre legitimados pelo poder do Estado. Ao impor o seu posicionamento, objeta nesse contexto enunciativo que a segurança e a repressão policial caminhem juntos para defender efetivamente as pessoas comuns, isto é, incapacitadas de portar armas para se protegerem, o que faz concluir, aos modos pêuchetiano e foucaultiano, que as transformações não aliviam a dominação. Há um silêncio constitutivo fazendo efeito nesses discursos, porquanto "se diz ' $\mathrm{x}$ ' para não (deixar) dizer ' $y$ " (ORLANDI, 2007, p. 73). O x é de fato o discurso que emerge a 
fundamentalização e a legitimação pelo poder do Estado, ou seja, armas somente nas mãos da segurança pública. Dessa forma, existe um efeito parafrástico caracterizando um anti-implícito "precisamos defender as pessoas comuns", criando uma barreira e impedindo que " $y$ ", isto é, o fato de a segurança pública ser insuficiente para guardar a defesa do cidadão, seja dito.

Diante do exposto, deparamo-nos com a disparidade na produção de sentidos no pronunciamento do atual presidente e do ex-presidente. O objeto segurança é paradoxal ao significar a partir de posições de sujeito que cada um deles assumiu ao dizer. Em Bolsonaro, a segurança do país estará garantida se o cidadão de bem possuir a posse e o porte de armas; em Lula, as pessoas comuns não vão dar segurança. Posto isso, como já perguntava Hamlet (SHAKESPEARE, 2012, p. 67-68) "Ser ou não ser, eis a questão. Será mais nobre sofrer na alma as pedradas e flechadas do destino feroz ou pegar em armas contra o mar de angústias e, combatendo-o, dar-lhe fim?". Nesse sentido, poderíamos levantar uma questão para o dilema: garantir a segurança ao manejar, sem preparo, uma arma para aludir à vida e à ação ou viver desprotegido sem o porte e a posse de armas aludindo para a morte e à inércia? Assim:

\begin{abstract}
A análise dos discursos [...] não procura o que é certo ou que é errado, muito menos procura "desvendar" o eterno dilema shakespeariano, no entanto, como vimos, ela é capaz de "destroçar" as evidências dos discursos e colocar questões para a ilusória concepção da clareza da linguagem. Dessa maneira, a $\mathrm{AD}$ de linha pecheutiana não procura se guiar pelo "ser ou não ser", mas pelo "como ser ou como não ser" nas posições discursivas. (BOUCHER; SOARES, 2020, p. 12).
\end{abstract}

Vejamos, ainda, como os efeitos de sentidos entre segurança e defesa da vida própria do cidadão de bem são articulados, em outro trecho da fala de Bolsonaro ao G1, em 10/5/2019:

Esperamos conseguir dar-lhe o excludente de ilicitude na defesa da vida própria e terceiros, ou de patrimônio próprio e de terceiros. Só dessa maneira, eu entendo, sei que não atinjo a maioria, mas talvez o suficiente para fazer valer essa máxima: a vida do cidadão de bem não tem preço. Àqueles que estão à margem da lei, paciência ${ }^{4}$.

No seguinte recorte "sei que não atinjo a maioria" é possível fazer trabalhar discursivamente "a maioria" como àqueles que não são a favor do porte e da posse de armas. Essa deriva encaminha para os sentidos de que o decreto é aceito pela minoria (ORLANDI, 2015). E mais uma vez essa minoria é representada pela vida do cidadão de bem marcada por uma sociedade de corte que insiste em se perpetuar e aproxima-se da prática de separar a sociedade em cidadão de bem posta em movimento desde a Grécia antiga pelo fato de só alguns terem privilégios sendo estes os proprietários de terras - homens livres para os negócios públicos, enquanto os demais eram excluídos de exercer a cidadania. Desse modo, o "[...] discurso da minoria revela a ambivalência intransponível que estrutura o movimento equívoco do tempo histórico" (BHABHA, 1998 , p. 222). Sobre a designação "cidadão de bem", marca no dizer a relação de

${ }^{4}$ Portal de Notícias G1. Foz do Iguaçu, 10 de maio de 2019. Disponível em: https://g1.globo.com/pr/oeste-sudoeste/noticia/2019/05/10/bolsonaro-diz-que-se-decreto-do-porte-dearmas-for-inconstitucional-tem-que-deixar-de-existir.ghtml Acesso em: 12 de jan. de 2020. 
identificação entre o locutor e o destinatário por ele projetado no dizer. Este "cidadão de bem" figura aqueles que elegeram Bolsonaro e passa a significar como sujeito colaborativo e confiante das decisões do governo.

A formulação " a vida do cidadão de bem não tem preço" pressupõe uma saturação do discurso segregador que joga com a inclusão e a exclusão quando o sujeito demarca e fortalece o valor da vida do cidadão de bem, revelando e separando também a vida do outro, o exterminável, o indesejável, o estranho que pela ordem do não dito e daquilo que é silenciado, são os que não concordam com o decreto do presidente. Este cidadão de bem, adjetivado por Bolsonaro, assemelha-se à "raça ariana" para Hitler. O comportamento de ambos se posiciona em separar às pessoas e conceder determinadas benesses àquele grupo que é intitulado superior. Para Arendt (2010, p.23) "[...] Ninguém que se tenha dedicado a pensar a história e a política pode permanecer alheio ao enorme papel que a violência sempre desempenhou nos negócios humanos, e, à primeira vista, é surpreendente que a violência tenha sido raramente escolhida como objeto de consideração especial [...]". Em suma, o discurso político põe em emergência as formações imaginárias através do cidadão de bem e o cidadão do mal, produzindo a inclusão de determinados sujeitos e o apagamento de outros.

Com efeito, o cidadão de bem mostra relações de exclusão, de oposição, de discriminação, migração de um discurso para outro, desenhado pela ideologia, pois há o compromisso desse dizer com a memória do nazismo. De acordo com Orlandi (2015, p.65) "As palavras refletem sentidos de discursos já realizados, imaginados ou possíveis. É desse modo que a história se faz presente na língua". A expressão de bem interpela o interlocutor a escolher o lado do bem com um efeito de "junte-se aos bons e serás um deles". Separam-se os campos do eu-nós e dos outros como campos opostos (CAZARIN, 2004, p. 187) do bem e do mal, a característica positiva do primeiro contra a característica negativa do segundo. Na apropriação social desse discurso, há regras silenciosas e variáveis, apresentando historicamente o Brasil que configura essa dicotomia do cidadão de bem e o cidadão do mal - bandido, o inimigo.

Dando elasticidade à expressão cidadão de bem, há movimentos contraditórios de sentidos quando se movem, se deslocam por cidadão do bem. Soares (2018, p. 191) afirma "Dizer de X é apagar os outros dizeres". É possível envolver entre o conceito "de bem" o indivíduo de Classe Média ou o rico e, assim, na articulação sintática "do bem implica" good citizen, pessoas honestas, de boa índole, de bom caráter. A designação cidadão de bem justifica-se nos pronunciamentos do presidente (CHARAUDEAU, 2015) pelos que devem ser protegidos, ou seja, o "povo" que legitima o discurso da violência e do preconceito e assim Bolsonaro utiliza-se desse jargão dos discursos políticos para acariciar a população que lhe aplaude. No efeito do deslize metafórico, que define o trabalho ideológico, está a constituição dos sentidos e dos sujeitos, pois o que é definido como "cidadão de bem" configura-se na pessoa que segue os valores tradicionais: a ética, a ordem e a moral, ou também pode ser definido como o político de determinado partido que, embora esteja envolvido em algum esquema de desvio de dinheiro público, é considerado "de bem" ou por que este cidadão não pode ser o estudante que fuma maconha na universidade e nunca teve uma passagem pela polícia? Decorrente desse raciocínio, o significado das palavras não se encontra na literalidade do signo, haja vista não existir um sentido específico. É no interior de uma formação discursiva que o significado de cada palavra aparece 
determinado. Nessa esteira, a ideologia dispõe de uma história própria, consequência da luta de classes, quer dizer, de uma história das sociedades de classes (ALTHUSSER, 1974).

Na sequência “Àqueles que estão à margem da lei, paciência” há a mobilização de um dizer que é marcado por um léxico de julgamento, produzindo um efeito de exclusão, conotação seletiva que remonta um discurso religioso no qual o efeito metafórico de separar o joio do trigo faz-se emergir. A formulação "à margem da lei" estabelece uma relação com o interdiscurso, ou seja, remete aos criminosos, bandidos, sinônimo de problema social, sem privilégios, homens e mulheres que encontram desprezo e violência. Ora, o contexto enunciativo "à margem da lei" envolve os que não concordam com o decreto do presidente e por isso são considerados bandidos? Destacase aí, uma confluência entre a memória que torna possível esse dizer e que representa o eixo da sua constituição, o interdiscurso (COURTINE, 1984). Mas, considerando também o funcionamento do intradiscurso, isto é, a formulação "à margem da lei" não representa os privilegiados, políticos, burocratas do alto escalão, os grandes empresários que tentam transgredir a lei para garantir os seus interesses? Dito de outro modo, é no jogo do equívoco que há sempre um processo polifônico de significações (ORLANDI, 2015) como diz o adágio popular "a lei não é para todos".

O dizer de Bolsonaro em "Esperamos conseguir dar-lhe o excludente de ilicitude" produz sentidos de legitimidade de uma política garantista que evoca uma licença para matar, uma receita para diminuir à violência. No verbo "esperamos", como marca da primeira pessoa do plural, configura-se um porta voz dirigente materializado na missão de salvar vidas, denotando nesse dito um efeito de legitimidade e de autoridade para poder fazer. É o que Indursky (2013) define como discurso manipulador que tira partido de uma posição de legitimidade, pois recorre a argumentos de ordem moral, acompanhados, quase sempre, de uma sanção em estado de potência. Esta divisão sintática entre nós e ele - o povo apresenta-se como um funcionamento separativo e de subordinação desse povo à posição de poder do presidente - efeito de potência para poder-fazer - quebrando o efeito de homogeneidade (CHARAUDEAU, 2016).

No sintagma verbal "dar-lhe" há uma interdição sobre quem se abrange nesse pronome "lhe", pois a igualdade social é inviabilizada nesse pronunciamento porque " $o$ povo" em sua totalidade não se inclui nesse decreto. Segundo Foucault (1996, p. 10) "Por mais que o discurso seja aparentemente bem pouca coisa, as interdições que o atingem revelam logo, rapidamente, sua ligação com o desejo e com o poder". É por meios e formas de "dizer" e "fazer" que os poderes vão sendo justificados nas sociedades. No recorte em análise, o presidente, ao enunciar o sintagma "dar-lhe", exerce um poder pelo seu discurso como forma de dominação, pois ao mesmo tempo que anui a posse e o porte de arma, controla aqueles que podem ter esse direito. É aí que se assenta a política ideológica do decreto, que a lei só alcança quem tem poder aquisitivo para comprar armas, aos relegados, é apenas uma letra morta.

Ademais, na expressão "Só dessa maneira, eu entendo, sei que não atinjo a maioria" é notório o posicionamento do enunciador em relação ao porte e a posse de armas, evidenciado na marca textual como "eu entendo" a materialidade no engajamento do porta-voz do povo em tentar resolver o problema da violência no Brasil 
como um problema social. Nessa perspectiva, Pêcheux (1990, p.17) define essa função de falar em nome de "expondo-se ao olhar do poder que ele afronta, falando em nome daqueles que ele representa, e sob seu olhar [...]" que o coloca em posição de negociador potencial, no centro visível de um nós em formação. Nota-se que, o sujeito ao dizer "Só dessa maneira, eu entendo, sei que não atinjo a maioria, mas talvez o suficiente para fazer valer essa máxima: a vida do cidadão de bem não tem preço" toma o poder de fala para si, porém o faz em nome de um "nós" que representa a coletividade, o povo. Para Charaudeau (2008b, p.58-59), o "discurso político se caracteriza por um jogo polêmico que utiliza constantemente contratos e estratégias para convencer ou seduzir o outro". Nas palavras do referido autor, no discurso político há uma construção e uma imagem de "fusão identitária" com o intuito de que todos os interlocutores sintam-se integrados.

Observemos outro recorte produzido por Bolsonaro, publicado no Estadão em 15/6/2019: "mais do que o Parlamento, precisamos do povo ao nosso lado para que possamos impor política que reflita em paz e alegria a todos nós" 5 . O fragmento "precisamos do povo ao nosso lado" mostra um funcionamento regular no discurso político brasileiro, a força do povo é dirigida a objetivos comuns e partilhada por todos, ou seja, o verbo "precisar" determina a participação do povo para que o decreto seja efetivado e assim a legitimidade dele é garantida. Ainda no pronunciamento "precisamos do povo" materializa-se a missão conferida aos brasileiros que apoiam o monopólio da violência, em um processo manipulador de assujeitamento no qual esse sujeito contribui para tal (ALTHUSSER, 1974).

Isso posto, o enunciador evoca o povo em uma participação ativa, inscrita na falsa aparência da política imaginária, revestindo-se em um simulacro do real. Nessa maquinaria político-ideológica, o chefe do executivo despe-se de sua individualidade, ao passo que se posiciona discursivamente, deixando o lugar de presidente, para humildemente pedir ajuda ao povo. Ousada manobra argumentativa mostra um intricado processo discursivo possível de apreender um efeito de inversão: tornar o povo frágil em privilegiado e o privilegiado em preocupado com as mudanças que beneficiarão a todos. Sob este prisma, é através do imaginário discursivo que os sujeitos projetam seus lugares, bem como dos seus interlocutores. Dessa forma, há uma inversão de papéis entre os protagonistas do discurso por meio de mecanismos que regem as formações imaginárias que o sujeito tem de si e do outro (ORLANDI, 2015).

Os argumentos usados pelo presidente em "precisamos do povo" são atos comunicativos de um enunciador que se utiliza da persuasão para convencer os interlocutores, denominado por Charaudeau de "O princípio de influência: todo o sujeito que produz um ato de linguagem visa atingir seu parceiro, seja para fazê-lo agir, seja para afetá-lo emocionalmente, seja para orientar seu pensamento" $(2005$, p.15). O discurso político "precisamos do povo" desempenha um papel fundamental na medida em que congrega, no contexto enunciativo, uma preocupação do enunciador para que o decreto seja efetivamente aprovado, daí a necessidade de influenciar o povo que o elegeu, evitando-se as opiniões divergentes à nova normatização. De acordo com Foucault (1996, p. 10) “o discurso não é simplesmente aquilo que traduz as lutas ou os

5 O Estado de São Paulo. Santa Maria (RS), 19 de junho de 2019. Disponível em: https://politica.estadao.com.br/noticias/geral,bolsonaro-defende-armar-a-populacao-contra-golpes-deestado,70002875064 . Acesso em: 12 de jan. de 2020. 
sistemas de dominação, mas aquilo por que, pelo que se luta, o poder do qual nos queremos apoderar".

Por seu turno, no recorte "para que possamos impor política que reflita em paze alegria a todos nós" depreende-se a filiação político-ideológica marcada nos sintagmas paz e alegria como resultado eficaz do decreto. Na sequência discursiva "paz e alegria a todos nós" podemos interpretar, pela ordem do não dito, que antes do decreto não existia paz para todos, apenas para alguns. É nesse efeito de sentido da palavra paz com sinônimo de harmonia, descanso contrapõe-se a arma com o sentido de segurança que pode causar a morte, também significando descanso, sossego, afinal, como diz o ditado popular, quando alguém parte dessa vida, "descanse em paz". Nesse deslizamento de sentidos, paz e alegria a todos nós" inclui tanto o sujeito enunciador como os cidadãos de bem e aqueles que serão vitimados com as consequências de se ter a posse e o porte de armas. Esse discurso político que ora desliza para o campo religioso, ao tratar a vida como valor sagrado, ora para o campo econômico quando a vida é comparada a um produto valioso que não tem preço, possibilitando estruturar a paz e alegria para todos, traduz-se como farsa, como engodo e como servil a alguma forma de poder (PÊCHEUX, 2010). No dizer presidencial "paz e alegria a todos nós” parece, ainda, haver um deslizamento nos sentidos mobilizados pelo imaginário de governo democrático, comprometido com o povo: a todos nós (COURTINE, 2006), restabelecendo a paz materializada no discurso de ódio, exclusão e extermínio, de modo a promover a segurança irmanadas ao porte e a posse de armas, contribuindo assim para a legitimação de Bolsonaro enquanto chefe de governo.

\section{CONSIDERAÇÕES FINAIS}

Conforme o objetivo deste trabalho, explícito no início do texto, e tendo como base os postulados da Análise do discurso francesa, esta pesquisa mobilizou leituras e interpretações sobre os dizeres do presidente Jair Messias Bolsonaro que nos possibilitou deslindar os interesses políticos internos no ato de conceder os benefícios para o povo possuir o porte e a posse de armas no Brasil, ancorado nos decretos assinados no decorrer do ano de 2019. Esta atitude, segundo o presidente, benéfica, posiciona-o como agente ideológico de transformação do mundo, efetivando o complexo processo de assujeitamento.

Nesse direcionamento, o presente estudo proporcionou a compreensão de como funciona os processos discursivos do atual presidente ao referir-se ao combate à violência no país, trazendo em seus dizeres um efeito de unidade entre ele e o povo que deve confiar ao seu governo a missão de combater à violência com armas. Os sentidos engendrados em tais discursos analisados são deslocados a partir da injunção das formações discursivas que determinam "aquilo que pode e deve ser dito" (PÊCHEUX, 2011, p. 73), pois, ao enunciar "povo" aponta para um dizer outro, produzindo sentidos que remontam a conflitos, nessa disputa pelo armamento ou não, quebrando com uma vontade una e hegemônica.

Como vimos, a partir da investigação dos enunciados trazidos à análise sobre o decreto 9785/2019, há uma relação contraditória frente àqueles que negam a unidade da vontade do "povo" e do "cidadão de bem" articulada pelo governo, apagando às posições reacionárias ao porte e a posse de armas. Em outras palavras, os sentidos 
produzidos a partir das formações discursivas na posição do sujeito presidente constituem-se contraditoriamente a outras formações discursivas que são injuntivas ao posicionar-se dessa forma e não de outra (ORLANDI, 2015), de modo que a produção dos sentidos não se pode dar pelo isolamento. Dessa forma, existe uma disparidade entre quem se inclui no direito outorgado pelo decreto e quem está à margem da lei. Ressaltamos, contudo, que alguns discursos foram ditos e outros silenciados, estigmatizados como subversivos a "uma política que reflita em paz e alegria para todos".

\section{REFERÊNCIAS}

ARISTÓTELES. Retórica. Tradução de Manuel Alexandre Júnior; Paulo Farmhouse Alberto; Abel do Nascimento Pena. Lisboa: Imprensa Nacional - Casa da Moeda, 1998. ALTHUSSER, L. Ideologia e aparelhos ideológicos de Estado. 3 ed. Lisboa: Editorial Presença/Martins Fontes, 1974.

ARENDT, H. A condição humana. 11. ed. Tradução: Roberto Raposo. Rio de Janeiro: Ed. Forense universitária, 2010.

BHABHA, H. K. O local da cultura. Belo Horizonte: UFMG, 1998.

BOUCHER, D. F; SOARES, T. S. Discurso do sucesso político e sucessalização nos dizeres de Donald Trump. In: Porto das Letras, v 6, n. especial, 2020.

CARNEVALE, A. M. Discurso e sujeito...um movimento de criação. In Soares, A. \& Ferrari, S et al. (Ed.). Discurso, resistência e... (p.67-72) Cascavel: EDUNIOESTE, 2015.

CAZARIN, E. A. Identificação e representação política: uma análise do discurso de lula (1978 - 1998). (Tese de Doutorado). UFRGS, 2004.

CHARAUDEAU, P. Uma análise semiolinguística do texto e do discurso. In: PAULIUKONIS, M. A. L. e GAVAZZI, S. (Ed.). Da língua ao discurso: reflexões para o ensino. (p. 11-27). Rio de Janeiro: Lucerna, 2005.

Discurso Político. São Paulo: Contexto, 2008a.

$2008 b$.

Linguagem e discurso: modos de organização. São Paulo: Contexto,

A conquista da opinião pública: como o discurso manipula as escolhas políticas. Trad. Angela M. S. Corrêa. São Paulo: Contexto, 2016.

COURTINE, J. Analyse du discourspolitique. In: Langages, n. ${ }^{\circ}$ 62, juin, 1981.

Définitions d' orientations théoriques et méthodologiques en analyse de discours. In: philosophiques. v. IX, n. 2. Paris, 1984.

O chapéu de Clémentis. Observações sobre a memória e o esquecimento na enunciação do discurso político. In: INDURSKY, F.; FERREIRA, M. C. L. (Ed.). Os múltiplos territórios da Análise do Discurso. (p.15-22) Porto Alegre: Editora SagraLuzzato, 1999.

Metamorfoses do Discurso Político: derivas da fala pública. Tradução: Nilton Milanez e Carlos Piovezani. São Carlos: Claraluz, 2006.

DUCROT, O. O dizer e o dito. Campinas: Pontes, 1987.

FERREIRA, M. C. L. Análise do Discurso e suas interfaces: o lugar do sujeito na trama dos discursos. In: Organon, (p. 17 - 35). Porto Alegre: UFRGS, v.25, n.48, 2010.

FOUCAULT, M. A Ordem do discurso. São Paulo: Loyola, 1996.

HAROCHE, C; HENRY, P. \& PÊCHEUX, M. A Semântica e o corte saussuriano: língua, linguagem, discurso. In: BARONAS, R. L. Análise do Discurso: apontamentos 
para uma história da noção - conceito de formação discursiva. (p. 13-32). São Carlos: Pedro \& João Editores, 2007.

HENRY, P. Construções relativas e articulações discursivas. In: Caderno de Estudos Linguísticos. Trad. João Wanderley Geraldi e Celene Cruz. n. 19. Campinas, 1990.

. Os fundamentos teóricos da "análise automática do discurso" de Michel Pêcheux (1969). In: GADET, F \& HAK, T. (org.). Por uma análise automática do discurso: uma introdução à obra de Michel Pêcheux. 4. ed. Campinas, SP: Ed. da Unicamp, 2010.

INDURSKY, F. A fala dos quartéis e as outras vozes. Campinas: SP: ed. da Unicamp. (título original, 1992), 2013.

ORLANDI, E. P. Discurso e texto: formação e circulação dos sentidos. Campinas, SP: Pontes, 2001.

As formas do silêncio: no movimento dos sentidos. $5^{\text {a }}$ ed., Campinas: UNICAMP., 2007.

Análise de Discurso: princípios e procedimentos. 12a Edição, Pontes Editores, Campinas - SP, 2015.

PÊCHEUX, M. Delimitações, inversões e deslocamentos. Tradução de José Horta Nunes. In: Cadernos de Estudos Linguísticos, (p.7-24). Campinas, v.19, 1990.

.; FUCHS, C. A propósito da Análise Automática do Discurso: atualização e perspectivas (1975). In: GADET, F.; HAK, T. (Ed.) Por uma Análise Automática do Discurso: uma introdução à obra de Michel Pêcheux. Tradutores Bethania S. Mariani... [et al.]. 3. ed. Campinas, SP: Editora da Unicamp, 1997a.

Semântica e discurso. Uma crítica à afirmação do óbvio/ Michel Pêcheux; tradução Eni Pulcinelli Orlandi... et al. Campinas: Editora da UNICAMP, 1998. . Papel da memória. In: ACHARD, P. (org.) Papel da memória. Tradução e introdução José Horta Nunes. Campinas: Pontes, 1999.

A análise de discurso: três épocas (1983) In: GADET, F.; HAK, T. (Ed.). Por uma análise automática do discurso: uma introdução à obra de Michel Pêcheux. 4. ed. Campinas, SP: Unicamp. (título original, 1969), 2010.

Língua, linguagem, discurso. In: PIOVEZANI, C, SARGENTINI, V. (org.). Legados de Michel Pêcheux inéditos em análise do discurso. São Paulo: Contexto, 2011.

ROBIN, R. L'Analyse du Discours entre la linguistique et les sciences humaines: l'éternel malentendu. In; Langages. (p: 121-127), 1986.

SHAKESPEARE, W. Hamlet. Tradução de Millôr Fernandes. Porto Alegre: L\&PM, 2012.

SOARES, T. B. Sucesso: discursos contemporâneos de capitalização dos sujeitos. In: Soares, T. B. (org.). Múltiplas Perspectivas em análise do discurso: Objetos variados. São Carlos: Pedro \& João Editores, 2018.

; SANTOS, Maycon Dougllas Vieira dos. (IM)prováveis presidentes do Brasil: uma análise das imagens de si nos pronunciamentos de posse dos presidentes Lula e Bolsonaro. Revista Humanidades e Inovação. v.7, n.24, 2021.

Artigo recebido em: out. de 2020.

Aprovado e revisado em: jan. de 2021.

Publicado em: fev. de 2021.

Para citar este texto:

FERNANDES, Elizangela Araújo dos Santos; SOARES, Thiago Barbosa. Discurso da luta contra a violência: O porte de armas e os seus efeitos de sentido. Entremeios [Revista de 
Estudos do Discurso, ISSN 2179-3514, on-line, www.entremeios.inf.br], Seção Estudos, Programa de Pós-Graduação em Ciências da Linguagem (PPGCL), Universidade do Vale do Sapucaí (UNIVÁS), Pouso Alegre (MG), vol. 23, p. 43-58, Edição especial/ 2020.

DOI: http://dx.doi.org/10.20337/ISSN2179-3514revistaENTREMEIOSvol23pagina43a58 